\title{
DE LA INVENCIÓN DE LA CIUDAD CULTA A LAS PRÁCTICAS COTIDIANAS
}

\author{
Danielle Provansal, \\ en colaboración con Cécile Miquel y Elisa Tabakman \\ Antropóloga, profesora de la Universitat de Barcelona/ERAPI \\ \&Antropóloga, Université de Toulouse-Le Miraii/ERAPI \\ \&Antropóloga, Universitat de Barcelona/ERAPI
}

Las autoras nos sitúan ante dos movimientos contradictorios entre sí: por un lado, los discursos o narrativas de la ciudad que tienden a concebirla como un proyecto global y, aunque inacabado, coherente sin embargo: la ciudad inventada; $y$ por otro lado, las prácticas urbanas singulares y múltiples que no se inspiran en ningún orden establecido: la ciudad prácticada. Aunque éstas últimas no suelen mencionarse como patrimonio a tener en cuenta por las primeras, poseen sin duda una capacidad para inscribirse en y escribir la ciudad. Esta dialéctica, y las cuestiones tanto urbanísticas como identitarias que suscita, es explorada tomando como ilustración el caso de la Ciutat Vella de Barcelona, espacio donde confluyen dos procesos simultáneos: las intenciones renovadoras y modernizadoras del urbanismo oficial y la instalación de muy diversas comunidades de inmigrantes.

$\mathrm{E}$ 1 antropólogo latinoamericano, Néstor García Canclini compara en uno de sus libros el modelo actual de ciudad a un videoclip, ya que, como éste, se parece a un «montaje efervescente de imágenes discontinuas». También, hace observar que frente a los fragmentos esparcidos del tejido urbano, las iniciativas de los poderes públicos y los discursos de los medias tienden a construir la ciudad como una totalidad imaginaria. Esto no tiene nada de nuevo. La ciudad como metáfora de la sociedad ideal y como culminación de la historia es una utopía recurrente en la historia de las sociedades humanas. Desde la polis ateniense, la «verdadera escuela del Helade» según Aristóteles hasta la cité radieuse de Le Corbusier, los ejemplos son innumerables: la ciudad ideal islámica encarnada en la Umma, la disposición armoniosa de los edificios y de los espacios en la Florencia de los Medicis que pretende reflejar el equilibrio de la relación entre la sociedad y el poder, el falansterio de Fourier, y más cerca de nosotros, las ciudades jardines que, en plena era industrial, sueñan con la naturaleza, sin contar las metrópolis que simbolizan un poder sagrado, como la ciudad imperial del Imperio del Medio o el Vaticano. De hecho, las sociedades que forman conjuntos a la vez compactos y polimorfos, son difícilmente aprehendidas fuera de su representación política y suelen ser pensadas generalmente a través de sus ciudades, de la misma manera que el poder busca reflejarse en su capital. 
Tomando prestada la imagen de Néstor García Canclini, nos encontramos frente a dos movimientos contradictorios pero cuya conjunción forma la realidad urbana. Por una parte, un discurso, a narrative, según la expresión postmoderna, que tiende a imaginar «totalidades», o dicho de otro modo, que hablan de la ciudad y la conciben como un proyecto coherente, como una producción cultural viva que, aunque inacabada, puede perfeccionarse en el transcurso del tiempo; por otra parte, prácticas urbanas singulares y múltiples que no se inspiran de ningún orden establecido pero que escriben la ciudad, trozo por trozo, islote por islote, fragmento de calle por fragmento de calle y la inscriben en un territorio con fronteras siempre movedizas. El resultado es una sucesión heteróclita de microcosmos atravesados por una infinidad de redes de sinergias paralelas, es decir, regidos por lógicas distintas y, a veces, contradictorias.

Nuestra intención es ilustrar estos dos aspectos de la realidad urbana mediante el ejemplo de Barcelona. Vamos a intentar confrontar la ciudad inventada y diseñada por los poderes públicos, los mass media y los urbanistas con la ciudad practicada y creada por sus usuarios. Los lugares elegidos para una observación etnográfica tienen un carácter emblemático en la medida en que representan o bien la memoria de la ciudad, el testimonio de su pasado, o bien su proyección hacia el futuro en tanto que portadora de modernidad. En esta presentación, nos hemos limitado a algunos escenarios del distrito de Ciutat Vella.

\section{La ciudad inventada}

Como bien se sabe, los Juegos Olímpicos de 1992 representan una referencia ineludible al respecto. Efectivamente, han proporcionado el marco ideal para la realización de grandes obras de infraestructura y de ordenación urbana y también para el lanzamiento de numerosas operaciones inmobiliarias de carácter privado, más o menos especulativas. La recuperación de antiguos barrios industriales caídos en desuso, la renovación de la Ciutat Vella, la creación de un frente marítimo y de varios grupos de inmuebles firmados por arquitectos muy prestigiosos han dado a Barcelona una dimensión internacional, inclusive mundial. Pero hay más. El reconocimiento, desde el exterior, de la ciudad de Barcelona se ha acompañado paralelamente de un poderoso fenómeno de reapropiación identitario. Gracias a una campaña de lanzamiento y de información sutilmente llevada a cabo por las instancias públicas, y más particularmente por la municipalidad, esta reapropiación ha sido vista como un verdadero don que los poderes institucionales han hecho a todos los Barceloneses, don milagroso que, como observa Juan de la Haba', le asemeja a un acto fundador y, como tal, le confiere un carácter sagrado que todos los ceremoniales de los mismos Juegos vienen a reforzar. Pero, además, a nuestro juicio, estos rituales tienen también la función de transformar la iniciativa pública en un acto de voluntad colectiva, para que la nueva Barcelona aparezca como la creación de todos sus habitantes. Prueba de ello el hecho de que éstos han participado masivamente en todos los acontecimientos urbanos vinculados a los 
Juegos y han hecho un uso amplio de las nuevas instalaciones -escaleras mecánicas de Montjuic, playas y Puerto Olímpico, pistas para ciclistas, nuevos espacios recreativos, pasarela del puerto viejo, Maremagnum, nuevo paseo de la Barceloneta, etc.

\section{Pensar la Barcelona del futuro: los planes estratégicos 2000}

Los Juegos han sido el pretexto a toda una reflexión, por parte de las instituciones, sobre el futuro de la ciudad y sobre las nuevas orientaciones a darle para impulsar su desarrollo en el contexto de la globalización. El primer plan estratégico (Plà estrategic 2000) es el instrumento creado a partir de 1988 para «pensar» y concebir la Barcelona del futuro. Este plan no se limita a elaborar una planificación urbanística de alcance general, sino que busca transmitir una concepción modélica de la ciudad de mañana. Se presenta de hecho como una especie de filosofía sobre la ciudad y la sociedad civil en su conjunto. Ésta es empero menos cercana de la utopía de la que hemos hablado al principio y se parece más bien a una plataforma programática capaz de orientar y hacer converger los diferentes intereses implicados. Aunque se trate de un órgano puramente consultivo, a la estricta función intelectual y planificadora, tiene sin embargo el objetivo de dejar su huella en los futuros proyectos de ordenación urbana. El primer plan, como los que les seguirán, reúne un abanico de participantes, de horizontes muy diversos: servicios urbanísticos, sociales y culturales de la municipalidad, representantes de empresas privadas y de diferentes $l o b$ - bies económicos, de las universidades y de Escuelas superiores ${ }^{2}$. Guía de orientación sobre el modelo de ciudad deseado, preconiza el cambio de vocación de Barcelona que debe sustituir su función industrial tradicional por la de «una ciudad empresa» especializada en el sector de servicios y dotada de la más sofisticada tecnología en materia informática y comunicacional $^{3}$. Sin exagerar, se puede decir que Barcelona busca colocarse lo mejor posible en el mercado globalizado de los espacios metropolitanos e incrementar su atractivo como lugar de residencia privilegiado para una elite cosmopolita y transnacional ${ }^{4}$.

Es interesante al respecto comprobar que todo un vocabulario tomado del higienismo inspira las diferentes versiones del Plà Estratégic 2000 o documentos referentes a acciones más específicas: así, por ejemplo, previamente a la edificación de la nueva Vila Olímpica, «la 49 vieja Icaria será construida como territorio estigmatizado, inerte, ocultándose la colonización de clase del espacio en términos de regeneración, de salud, en donde confluyen discursos higienista y metáforas médicas (»abrirlo a las benéficas brisas marítimas», abrir «pulmones», «airear, «esponjar»y «rejuvenecer» el espacio, hacer «trasplantes» 0 «inyectar transfusiones» que «revitalicen», eliminar la «peligrosidad social...»

Este comentario se refiere al barrio del Poble Nou, antiguo suburbio industrial cuya parte litoral ha sido englobada en la Villa Olímpica y que actualmente está sometido a otras acciones de renovación. Sin embargo, expresiones del mismo tipo han sido y están siendo utilizadas para otros lugares destinados a ser renova- 
dos, como ocurre en el districto de Ciutat Vella. Los Barceloneses han sido movilizados para esta gigantesca operación de limpieza metropolitana, mediante campañas de sensibilización pública y consignas del tipo «Barcelona, posa-t guapa» o «Barcelona, posa-t neta». No está de más subrayar que este deseo de higiene no se refiere únicamente a la limpieza de los edificios y de los espacios públicos, sino que tiene también un significado de higiene social. De hecho, en los barrios que componen el actual distrito de Ciutat Vella residen la gran mayoría de los inmigrantes extranjeros $y$, en particular, los que no tienen permiso de residencia. Si bien uno de los núcleos del distrito, el antiguo Barrio Chino, había sido, desde el principio del siglo y durante el franquismo, el escenario de la prostitución, de la delincuencia y de alguna que otra actividad ilícita, la imaginería popular la había integrado como algo típicamente barcelonés, como la revancha «canalla» de los barrios más convencionales y más burgueses, como algo familiar y propio que la llegada de extranjeros de muchos horizontes diversos ha alterado. La existencia de puntos convenidos para la venta y compra de droga, asimilada erróneamente en la mente colectiva a la exclusiva presencia de éstos extranjeros, ha cambiado la fisionomía del barrio y le da un aspecto equívoco del que los residentes autóctonos se quejan a través de sus asociaciones de vecinos, exigiendo más seguridad urbana y mayor presencia policial. Esta reivindicación se refleja, de forma eufemística, en el I Plà Estratégic mediante el compromiso institucional de conseguir «la cohesión social» entre las diferentes clases de residentes.
El II Plà Estratégic ${ }^{6}$ pone el acento en la cultura como medio para hacer de Barcelona la «ciudad del conocimiento». Se trata de una definición de cultura ampliada, como lo precisa el documento, que enfoca en la era informacional los vínculos entre la cultura y la ciudad en términos de centralidad. Su objetivo es orientar la ciudad hacia un desarrollo sostenible, partiendo de la hipótesis que «las ciudades tienen la capacidad de proyectar ecosistemas culturales vivos y en confrontación permanente». Los objetivos marcados por la Barcelona cultural de 2010, con la fase intermedia del Forum 2004 requieren por un lado una redefinición de las relaciones entre público y privado, entre local y universal y entre tradición e innovación y, por otro lado, un desarrollo de las técnicas de comunicación: Barcelona tiene la ambición de convertirse en ciudad «digital» y también, en «manufactura productora de bienes culturales». Por ello, el II Plà se compromete también a reactivar el patrimonio histórico y artístico de Barcelona, no solamente los museos, los jardines, los edificios medievales o modernistas, sino, además, según la formula del documento «las expresiones culturales inmateriales», o dicho de otro modo, las formas de vida cotidiana, los usos de la calle, las fiestas y las tradiciones: «La ciudad debe ser capaz de valorar este patrimonio urbanístico como la mejor garantía para expresar su singularidad en un contexto cada vez más global» ${ }^{7}$.

Algunos de los núcleos del distrito de Ciutat Vella forman parte de este patrimonio a salvaguardar o a reactivar, de allí el interés en mencionar esta frase. El objetivo es, siempre 
según el documento «gestionar el paisaje urbano como patrimonio cultural colectivo y descodificar los símbolos que contiene para transmitirlos al conjunto de la colectividad» ${ }^{8}$.

Esto significa de manera implícita crear, o mejor dicho, fabricar una identidad urbana común, independientemente de los orígenes y de las diversas tradiciones. Significa en resumidas cuentas ser «barcelonés» $y$, por otra parte y al mismo tiempo, participar en una cultura global. El vocabulario higienista ha sido sustituido por una perspectiva más social que preconiza «garantizar un clima de aceptación y de preservación de los nuevos ciudadanos procedentes de otros continentes». Para atajar las consecuencias nefastas de la marginación y favorecer la tolerancia recíproca, se reafirma públicamente en este documento la voluntad de seguir con las prácticas adoptadas, desde algunos años, hacia todos los residentes, independientemente de su estatus legal, a saber el acceso a la asistencia sanitaria y a la educación pública. También se preconiza la creación o el reforzamiento de plataformas de diálogo entre las asociaciones de vecinos, los diferentes colectivos inmigrados, las ONG, la administración local y los agentes sociales.

El documento más reciente del Plà Estratègic $^{9}$ retoma las grandes orientaciones enunciadas en los dos primeros y precisa las modalidades de su aplicación. Además, se insiste en él en la capacidad de innovación como aspecto ineludible de la vocación de conocimiento y sobre la heretogeneidad como aspecto imprescindible para la creación. Esta heterogeneidad asociada a la complexidad funcional del territorio está invocada para romper con un modelo urbanístico basado en la especialización de las diferentes áreas y para preconizar la mezcla de funciones en una misma porción del territorio.

Aunque, en uno de estos documentos, las prácticas cotidianas están mencionadas como patrimonio a tener en cuenta, no parecen estar enfocadas en su capacidad de producción de la ciudad misma, o, si se prefiere, de su transformación incesante. No obstante, las trayectorias y las redes étnicas, así como la apropiación de lugares mercantiles o culturales por parte de extranjeros no pueden ser obviadas y estos mismos extranjeros no pueden ser ignorados o exclusivamente contemplados en términos de marginación y de seguridad urbana, ni tampoco ser solamente enfocados, a partir de una perspectiva miserabilista, es decir de la explotación a la que están sometidos, en lo que se refiere al trabajo o al alojamiento. Por cierto, esta explotación existe pero también existen estrategias individuales o comunitarias que tienen como finalidad mejorar el marco cotidiano y que tejen entre los autóctonos y los recién llegados vínculos complejos, a veces conflictivos, pero que contribuyen a hacer de la sociedad barcelonesa algo completamente diferente de lo que era unos treinta años atrás.

De hecho, esta filosofía urbana, tal como se refleja en los documentos mencionados, está muy alejada de la realidad cotidiana, al menos para el barrio que nos ocupa; esto nos lleva a pensar que, como modelo ideal transmitido por las diferentes instituciones competentes en la materia, sirven ante todo de garantía 
estética y ética a las operaciones de cirugía urbana practicada sobre Barcelona, durante la última década. A pesar de que los diferentes planes urbanísticos de rehabilitación o de mejora de los barrios (PERI ${ }^{10}$ ) hayan tenido apreciaciones muy diversas en cuanto a su aplicación, tal como se refleja en una publicación reciente editada por el Ayuntamiento de Barcelona" y en las entrevistas que hemos realizado a los residentes, existe un indudable desfase entre el modelo urbanístico institucional y las expectativas de los usuarios. Eso puede parecer chocante ya que las asociaciones de vecinos participaron en la elaboración de estos planes, a partir del primer gobierno municipal democrático. Sin embargo, varias razones nos ayudan a entender esta aparente contradicción. En primer lugar, los planes han sido sometidos a repetidas modificaciones que, en muchos casos, ha desvirtuado los objetivos iniciales $^{12}$, por ejemplo, la sustitución de las zonas verdes previstas por inmuebles de alquiler, de poca calidad, o por áreas de descampado, todavía sin función precisa que da al barrio un aspecto de provisionalidad; el carácter desangelado y artificial de algunas de las nuevas vías abiertas o de alguna que otra plaza concebida arbitrariamente para ser espacios de sociabilidad, pero que, al carecer de viviendas o de comercios, e inclusive, a veces de arboles o de bancos, se convierte en plaza «fría», permaneciendo inhóspita y desierta, a partir del anochecer. Pueden de hecho estar asimiladas a no-lugares por la falta de animación que les caracteriza. La sociabilidad no se inventa, dibujándola simplemente en una hoja; $y$, como lo subraya Lapeyronnie a través de su crítica del «modernismo racionalizador», tampoco se puede planificar.

El desacuerdo entre planificadores y usuarios es más o menos acentuado según las expectativas de éstos últimos y según su nivel social. Como lo subraya Ubaldo Martínez ${ }^{13}$, algunas partes de Ciutat Vella han experimentado un inicio de gentrificación. Éste es aún lento, comparado con lo que ha ocurrido en otras ciudades europeas (París, por ejemplo) y afecta núcleos muy precisos, sobre todo el norte del sector occidental o barrio del Raval, la calle Ferràn que une Les Ramblas a la Plaza Sant Jaume, el barrio gótico, y algunos edificios del sector oriental, en torno al antiguo mercado del Borne y cerca de la iglesia de Santa Maria del Mar. El resto queda igualmente degradado o sometido a operaciones de demolición a gran escala y de reconstrucción de inmuebles baratos para proporcionar alojamiento a los residentes afectados ${ }^{14}$. Esto hace que los residentes autóctonos de clase media forman islotes privilegiados pero segregados en un entorno que está lejos de corresponder a sus aspiraciones. En las áreas aún no sometidas a rehabilitación, se aloja la mayoría de la población en la que se mezclan autóctonos sin recursos o con recursos precarios -estudiantes, personas de la tercera edad, parados, okupas, marginales-e inmigrados de procedencia muy diversa, entre los cuales muchos no regularizados. Al respecto, nos parece significativo que las principales reivindicaciones de la asociación la más combativa del sector oriental, Veins en Defensa de la Barcelona Vella, que se expresa a través de un boletín Perillem, se refieran a la defensa del patrimo- 
nio del barrio y al valor histórico y arquitectónico de varios palacios cuyo estado de degradación les condena al derribo. Se lamentan también de la mala calidad y de la falta de estética de algunas de las nuevas construcciones poco acordes con el patrimonio arquitectónico existente. Además, en su imaginario colectivo, son los marginales, los delincuentes y drogadictos los que han copado los principales espacios públicos del barrio. Culpan de ello al Ayuntamiento que, por descuido, por falta de medios $o$, inclusive, por voluntad deliberada de favorecer el negocio de las grandes empresas inmobiliarias, no asumiría la responsabilidad que le incumbe en materia de orden público y de seguridad urbana y dejaría el barrio a su suerte. Por supuesto, hay delincuentes y drogadictos en el barrio y sus casas abandonadas constituyen escondites cómodos. Algunos lugares, además, sobremanera conocidos de los autóctonos están ritualmente destinados a la venta de hachís o de heroína. Por añadidura, la policía parece omnipresente, de día como de noche, en uniforme, en civil, en moto, en coche o en furgoneta. Es posible sin embargo que, según la época del año, la vigilancia sea más o menos eficiente. Con la llegada de la primavera, se multiplican los grupos de turistas y visitantes. Al limpiar los barrios históricos de sus elementos indeseables, se contribuye a mantener una imagen de Barcelona acorde con el turismo de calidad que, según los Planes estratégicos, se pretende atraer.

De hecho, la amalgama que se forma entre la presencia de extranjeros indocumentados que se instalan en el barrio y la existencia de acti- vidades ilícitas no refleja el mapa real de los espacios y de sus funciones, las fronteras invisibles que separan las diferentes categorías de residentes, según la hora y según el lugar preciso, ni tampoco da constancia de la presencia abierta y dinámica de los pequeños comercios étnicos que dan vida a calles que, de otro modo, se hubieran quedado desfasadas, ni tampoco de la clientela, también étnicamente muy diversa, que viene a suministrarse en ellos. Tanto los documentos reunidos en los planes estratégicos, como los documentos producidos por las asociaciones de barrio tratan de los diferentes colectivos de extranjeros instalados en el barrio, no como «residentes», sino como «huéspedes», entre los cuales algunos potencialmente peligrosos por ser indocumentados, que conviene «integrar». El término se presta a todas las ambigüedades: según el caso, puede significar «silenciar», «convertir en invisibles», como «asimilar» o «controlar». La afirmación de la necesidad de integración plantea, como paso previo, la necesidad de erradicar la clandestinidad y, seguidamente, la conveniencia de gestionar y canalizar la «diferencia». Pocas alusiones están hechas en estos documentos a la pluralidad étnica y cultural como elemento de enriquecimiento mutuo de los grupos que componen la sociedad civil. Los extranjeros permanecen extranjeros, inclusive cuando, por razones pragmáticas, se considera conveniente que se conviertan en «ciudadanos». Por ello, nos parece que el discurso eminentemente crítico que algunas asociaciones de vecinos emiten sobre las intervenciones urbanísticas públicas y privadas, si bien contradice el discurso oficial, mitificante y mitificado, está muy lejos de la realidad 
cotidiana, tal como se desarrolla en los diferentes núcleos de Ciutat Vella.

\section{Prácticas urbanas o la otra manera de crear la ciudad}

Hemos elegido dos escenarios para subrayar el contraste entre la ciudad inventada -la que se desprende del discurso urbanístico, y en menor medida, de las asociaciones de vecinos- y la ciudad practicada -la que emerge de los usos cotidianos-. El primero se centra en la plaza donde se sitúa el Museo de Arte Contemporáneo de Barcelona (MACBA), en pleno Raval. El segundo se encuentra en el Casc Antic: se trata de una calle peatonal que lo atraviesa de par en par, desde la Vía Laietana hasta la Plaça Sant Agustí Vell. Esta calle que empieza llamándose carrer Bòria, cambia de nombre, después de atravesar una pequeña plaza triangular llamada Plaça de la Llana, llamándose carrer Corders para finalmente desembocar en la plaça Augusti Vell con el nombre de carrer Carders.

Mientras el primer escenario remite a la Barcelona del siglo XXı y prefigura la capitalidad cultural que la ciudad se ha otorgado en fechas futuras, el segundo escenario remite a la Barcelona del pasado, cuyas funciones se han van redefiniendo con el paso del tiempo.

El espacio en que se encuentra el Museo de Arte Contemporáneo, en el centro del Raval, es un ejemplo paradigmático de aquellas plazas frías, desprovistas de ornamentación y de vegetación, que se han multiplicado en BarceIona en los últimos años y pretenden evocar la ciudad post-olímpica y post-moderna, funcio- nal y sobria. Los rollers y los patinadores invaden la calzada y la escalinata del edificio del arquitecto R. Meier cuya blancura inmaculada contrasta con los inmuebles de frente condenados al derribo y con el descampado colindante transformado en pista de baloncesto improvisada. Frente al museo, se encuentra el antiguo convento dels Angels que da testimonio del pasado histórico de la ciudad pero que, en este desorden urbanístico dominado por lo inacabado parece haberse equivocado de sitio. $Y$ frente al antiguo convento, un edificio antiguo pero renovado con grandes cristaleras, mezcla patrimonio y modernidad $^{15}$. Por la mañana, los autobuses de turistas vierten en la plaza su contingente de fotógrafos compulsivos. En las tardes de verano, la plaza se anima con vecinos del barrio. Hasta el verano pasado, un grupo de mujeres magrebíes se instalaban a la fresca, apoyadas a un pequeño muro frente al museo. Solían ocupar el mismo lugar, mientras sus hijos iban zigzagueando delante de ellas. Cochecitos de niños y carros de la compra les servían de muralla contra eventuales intrusiones. Se apropiaban así de una porción del espacio público, pero de forma exclusiva, es decir sin dejar a ocasionales paseantes la posibilidad de compartirlo. Lo habían convertido así en lugar de «privacy» que reproducía en un sitio exterior, abierto en principio a todo el mundo, la clasificación de los espacios por género que caracteriza al universo magrebí y las prohibiciones que les rigen. Los pocos hombres magrebíes que atravesaban la plaza a esta hora lo sabían muy bien: guardaban las distancias para evitar romper el carácter haram -o sagrado- que rodeaba a este grupo 
de mujeres. Éstas han desaparecido hoy de este escenario barcelonés: el muro ha sido derribado y sustituido por una vía de acceso a un parking subterráneo cuya entrada peatonal -de acero y cristal- ocupa el centro de la plaza.

Por contraste, los grupos de latinoamericanos y de filipinos tienen por costumbre acampar en el mismo centro de la explanada. El núcleo formado por la red de callejuelas que rodean la plaza y la conecta con el mercado de la Boquería representa para ellos un lugar de centralidad y también de referencia. El Centro Filipino está situado cerca de allí, en el carrer Riera Baixa y celebran diferentes ceremonias religiosas en la iglesia que se encuentra detrás del MACBA, en la plaza Joan Corominas. A la salida de la iglesia, las primeras comuniones, las bodas suelen reunir a la comunidad. Durante algunos instantes, el barrio se convierte en un «barrio filipino» ${ }^{16}$. Estas diferentes puestas en escena, cuya dramaturgia remite a códigos culturales exóticos, o sea lejanos, constituyen otras tantas formas de arraigamiento a los nuevos lugares de residencia, para que éstos se llenen simbólicamente y se conviertan en significantes, integrándose en su proyecto étnico, de la misma manera que sus lugares de origen; en resumidas cuentas transformándose en etnoscapes, según el término utilizado por A. Appadurai ${ }^{17}$.

Hay días en que la plaza del museo sirve para uno de estos happenings contemporáneos llamados manifestaciones artísticas; el público cambia entonces: personas vestidas de forma informal pero a la última moda invaden los espacios que los otros ocupantes habituales han dejado. A veces, una tienda está levantada en medio de la explanada en torno a la cual toda esta gente selecta se mueve, se saluda, charla, bebe una copa, fuma algún cigarrillo, confiriendo al lugar la función que los poderes públicos le habían atribuido. La capilla del antiguo convent dels Angels, recientemente restaurada, sirve también de sala de exposición. Los montajes vanguardistas que se exponen allí atraen generalmente un público joven en el que se mezclan «pijos", "progres» o representativos de culturas alternativas que ocupan el ángulo de la plaza, aquel en el que las mujeres magrebíes solían instalarse. La marihuana que se consume en esta circunstancia no tiene nada que ver con las drogas que, unos centenares de metros más lejos, pequeños traficantes clandestinos -extranjeros u autóctonos- venden a los consumidores procedentes de diferentes partes de la ciudad.

Tenemos aquí el ejemplo de un decorado inacabado, como lo demuestra el descampado en el que deberá instalarse la futura Facultad de Geografía e Historia de la Universidad de Barcelona, en el que se mueven personas o grupos que no tienen ningún vínculo los unos con los otros, pero que superponen en el tiempo diferentes representaciones de la ciudad: la ciudad soñada por los poderes públicos que reúne cultura y urbanismo renovado en lo que fue el viejo centro canallesco e intérlope de la ciudad ${ }^{18}$, el lugar de paseo artístico y mundano de las elites que, mediante un reconocimiento visual efímero, se reapropian simbólicamente uno de los lugares más emblemáticos de la Barcelona literaria e inconformista, turistas transforma- 
dos, a marchas forzadas, en obligados consumidores culturales, lugar de reunión de comunidades étnicas esparcidas en diferentes puntos de la urbe, ancianos españoles y catalanes, diversas clases de extranjeros, de paso, residentes, documentados o indocumentados, pandillas de «niños de la calle», procedentes del Magreb, mediadores interculturales, pequeños comerciantes ambulantes o traficantes, drogadictos, prostitutas, travestís, intelectuales o artistas con ansias de inspiraciones fuertes y un largo etcétera. Esta multitud de elementos se componen, se descomponen y se recomponen como figuras de caleidoscopio, según la hora o la temporada y contribuyen a dar una imagen fragmentada de la ciudad. Otros signos, sin embargo, siempre en Ciutat Vella, contribuyen a crear un decorado más duradero, cuyo carácter exótico contrasta fuertemente con los otros barrios de Barcelona y con sus manifestaciones periódicas de catalanidad, con las banderas colgadas en las fachadas, los días de la Diada, de Sant Jordi y de las fiestas de la Mercè. Estos signos enuncian - $y$ anuncian- transformaciones profundas en el paisaje urbano y en sus actores.

\section{Asentamiento, especialización y afirmación étnica}

Durante la década anterior, el comercio étnico se ha desarrollado en las principales vías de Ciutat Vella y ha conquistado algunas paradas en el mercado de la Boquería ${ }^{19}$. A pesar de que los paquistaníes están preferentemente especializados en los bazares electrónicos, los chinos en restaurantes y tiendas de alimentos exóticos, los magrebíes en carnicerías El
Hallal, los latinoamericanos en bares, las africanas y las dominicanas en peluquerías, no se puede hablar por ahora de una estricta especialización étnica y aún menos de enclaves étnicos, a pesar de que, a menudo, estas tiendas transforman sus mercancías para adaptarlas al gusto de la clientela y suelen frecuentemente cambiar de propietario o de gerente, siendo entonces el traspaso generalmente efectuado en el marco de los lazos de parentesco ampliado o de la red étnica. Empero, la afirmación de la pertenencia étnica se manifiesta de forma casual y puntual en determinados bares o en pequeños restaurantes cuya clientela suele ser mayoritariamente $-y$ a veces exclusivamente- del mismo origen étnico. Por consiguiente, las fronteras entre las diferentes categorías de extranjeros son aún provisionales y movedizas, ya que éstos tienen una relación bastante fluida con el territorio. Un día aquí, otro día allá. Las agrupaciones que se forman en algunos momentos son más o menos efímeras y no marcan límites estrictamente definidos entre las diferentes comunidades extranjeras o bien entre éstas y los residentes catalanes y españoles y sugieren más bien la idea de una negociación constante de los lugares cotidianos, sobre todo los de ocio. Vamos a dar una ilustración concreta inspirada de nuestras observaciones en el sector oriental de Ciutat Vella.

En este núcleo, los movimientos de los residentes y transeúntes sugieren más bien la imagen de un encajonamiento de los usos en el tiempo, como ocurre en el escenario del Raval que hemos descrito antes, pero donde los actores externos -turistas, intelectuales y 
«gente guapa»- no franquean ciertos límites que se sitúan al norte del barrio, en la calle Sant Pere més Alt, una vez pasado el Palau de la Música; al sur, a partir del carrer Princesa, en el pequeño núcleo emblemático constituido por el carrer Moncada, el Paseig del Born y Santa María del Mar. Justamente, nuestros escenarios de observación, para el sector oriental de Ciutat Vella, se sitúan más allá de esos límites.

\section{El ir y venir cotidiano}

A lo largo de la semana, por la mañana temprano, son los autóctonos, generalmente personas mayores, los que atraviesan el barrio para ir al mercado ${ }^{20}$. Algo más tarde, las mujeres magrebíes, generalmente en grupo, más raramente solas, acompañan sus hijos a la escuela del barrio o van también de compras. Sus idas y venidas se caracterizan por su extrema discreción. Mientras las tiendas administradas por autóctonos tienen horario fijo, la apertura y el cierre de los comercios étnicos varían, para adaptarse a los hábitos de su clientela. Hacia las 19 h., la animación está en su punto culminante y es la hora en que los límites étnicos son más visibles. La población dominica, principalmente femenina, ocupa la parte de la calle Bòria, adosada a la Via Laietana, seguida por africanos subsaharianos agrupados en torno a una tienda de «música afro». A continuación, son los magrebíes que ocupan el resto de la calle, así como una parte de la plaza Sant Agustí Vell que comparten con jóvenes autóctonos, algunos entre ellos, con vestimenta aparatosa o corte de pelo que se inspiran de modas subalternas o contraculturales. Paralelamente, las calles de Bou de
Sant Pere, Argenter, d'en Monec que se encuentran cerca del Palau de la Música, evocan a veces el centro de una medina, al llenarse al anochecer, en primavera y verano, de marroquíes que toman el aire sentados en la misma acera, apiñados y conversando en voz alta.

La presencia de asiáticos -pakistaníes, hindúes o chinos- es menos perceptible en el espacio público, aunque algunos pakistaníes se dejan ver los viernes hacía los centros de culto, vestidos según el modo tradicional, mezclándose con otros musulmanes, magrebíes o africanos subsaharianos. La visualización de esta $U m m a^{21}$ en el espacio barcelonés, aunque sea solamente una vez a la semana, nos hace pensar que el islam es un poderoso instrumento para abolir la ley de la aç̧̧abyia ${ }^{22}$ e impedir la aparición de fronteras étnicas permanentes y conflictivas, al menos entre los que practican el islam. ¿Hasta qué punto, a partir de rituales compartidos, no se está configurando un marco de adscripción más amplio que englobaría todo «lo musulman», frente a la sociedad receptora, la cual percibiría igualmente esta línea divisoria y contribuiría a consolidarla? Las ocupaciones y manifestaciones recientes nos incitan a pensar en el carácter operativo de este marco, al menos frente a la sociedad catalana, lo cual no suprime por supuesto el orden jerárquico, de carácter étnico, interno a las sociedades de origen.

Los pakistaníes sikhs, reconocibles por sus turbantes, son los que franquean con más facilidad los linderos del vecindario con los latinoamericanos, en particular, los dominicanos, 
circulando por las Ramblas, la Plaza Cataluña, e inclusive más allá, en la parte central del Ensanche. Pero volviendo a Ciutat Vella, no podemos dejar de observar cómo, de forma creciente, algunas tiendas enarbolan rótulos en lenguas nativas, al lado de un rótulo en catalán. Esto tiene la función práctica de avisar a la clientela potencial, del mismo origen étnico, que encontrará productos familiares y para las carnicerías magrebíes, que la carne que venden está matada ritualmente, y por consiguiente, lícita para el consumo de los musulmanes. Al mismo tiempo aporta la prueba de una apropiación del territorio de adopción mediante una designación que remite al territorio de origen, es decir, hace visible la construcción de un ethnoscape.

\section{La porosidad de la cultura}

Esta breve descripción de algunos escenarios urbanos fuertemente localizados en el espacio barcelonés nos lleva a abordar la cuestión de la representación social que suscita, representación que, por otro lado remite a la problemática identitaria, si se admite que la representación del otro es inseparable de la representación de lo propio. Para sintetizar, se puede decir que, aparte de algunas excepciones que no confirman en absoluto la regla, estos nuevos actores en la escena barcelonesa emergen en la percepción colectiva, no como ocurría al principio de la inmigración extranjera, como figurantes mudos de la dramaturgia que la ciudad busca proyectar al exterior y que, de paso, se representa a sí misma, pero como actores que desempeñan su papel en otra escena, en un escenario paralelo y secun- dario que solamente coincidiría puntualmente con la trama principal. El hecho de que estén agrupados preferentemente en algunos lugares más que en otros facilita este tipo de representación; lo mismo ocurre con los espacios compartidos, ya que los usos que se hacen de ellos y los instantes en los que están utilizados no son siempre los mismos. En su conjunto, la sociedad barcelonesa no se representa, ni se piensa todavía como sociedad mestiza. Las diferentes celebraciones colectivas que se organizan para manifestar una solidaridad con los inmigrados, indocumentados o regularizados, como las fiestas de la convivencia o de la solidaridad, así como las manifestaciones contra el racismo o la nueva ley de extranjería son actos eminentemente ritualizados, durante los cuales autóctonos e inmigrados comparten un mismo espacio reivindicativo y establecen un contacto que suele ser mucho más esporádico en la vida cotidiana para la mayoría entre ellos. Podríamos designar estas diferentes manifestaciones bajo el nombre de «ritos»o «rituales de comunicación», porque rigen y regulan los únicos momentos y los únicos lugares en los que parte de la sociedad barcelonesa se convierte verdaderamente, aunque de modo efímero, en una sociedad mestiza.

La (re)construcción identitaria que se ha hecho bajo el franquismo, y también después, a reforzado una imagen del nosotros constante en el tiempo. Por otra parte, en la época de la globalización, la catalanidad sirve para reafirmar la fuerza de lo local. Barcelona no es toda Cataluña, sólo es su capital; capital que las otras ciudades de menor importancia y las 
zonas rurales miran con desconfianza, dado su parti-pris de «sobremodernidad» y su proyección hacia el exterior. Sin embargo, la catalanidad, como reivindicación de un patrimonio cultural e histórico propio, permite a los poderes públicos, en particular los municipales, establecer un lazo entre el pasado y el reto del futuro. Es este mensaje que buscan transmitir y que la sociedad autóctona parece asumir. Esto tiene inconvenientes. El principal, a nuestro juicio, es cierta cristalización identitaria -a no confundir con una crispación identitaria-. Esta cristalización que incita a colocar los «otros» actores urbanos «de lado» con relación al escenario principal contribuye también a acuñar una representación de éstos igualmente petrificada. Hay un discurso oficial, insidiosamente paternalista, que habla de la cultura y de la proyección de la cultura como de un capital que se alteraría al contacto de otros modos de hacer, vivir y pensar. No obs- tante, basta observar los lugares de lo cotidiano para tomar consciencia de la «porosidad» de las culturas, según la expresión de Isaac Joseph ${ }^{23}$. Según este autor, la etnicidad sería un subproducto de la ciudad. Podríamos seguir en la misma línea y decir que nuevas expresiones de pertenencia étnica se elaboran en el seno de la ciudad y que los espacios públicos constituyen el laboratorio en donde se forman, mientras que el migrante aprende a transitar de un modo cultural a otro, sin que ello signifique una pérdida de identidad. Podríamos decir también que a los itinerarios nómadas les corresponden identidades «fluidas» e, inclusive híbridas, para retomar la expresión de Néstor García Canclini ${ }^{24}$. Los autóctonos, sean cuales sean, donde estén, tienen el reto de tomar el mismo camino y hacer el aprendizaje de la movilidad de las identidades, de su identidad en el seno del espacio público.

\section{NOTAS}

1 J. de la Haba (1999): «La ciudad y sus metáforas. Formulación ideológica y procesos de reestructuración urbana en la Barcelona contemporánea», Astrágalo, núm. 12, pp. 43-67.

${ }^{2}$ J. de la Haba, op.cit., p. 63.

${ }^{3}$ P. López (1991): «Barcelona Olímpica. Objectiu de tots?», Revista Catalana de Geografía, núm. 15, pp. 91-99.

${ }^{4}$ M. Castells (1997): La era de la información. La sociedad red, Madrid, Alianza Universidad.

5 J. de la Haba, op.cit., p. 55.

- Su elaboración se inició en enero 1998 y fue presentado públicamente el 5 de mayo de 1999. El texto de este documento se encuentra en la página web: http://WWW.bcn. es/icub/accentcultura/cast/m_com.htm.

${ }^{7}$ Ibid, IV-La arquitectura del Plan: http//www.bcn. es/icub/accentcultura/cast/4.htm, p. 2.

${ }^{8}$ Ibid, V-Los contenidos del Plan: Propuesta organizativas y proyectos de actuación. Untitled Document: http//www.bcn.es/icub/accentcultura/cast/5.htm, p. 7.
9 XVI Jornada Tècnica de l'Associació Plà Estrègic Barcelona 2000, 17 diciembre de 1998.

${ }^{10}$ Plà Especial de Reforma Interior.

"VVAA, Escenes del Raval, una instal lació activa, Centro de Cultura Contemporània de Barcelona, Ajuntament de Barcelona, 1999.

${ }^{12}$ Por ejemplo, en el caso del barrio Casc Antic: PERI del Sector Oriental (aprobación inicial: 1983), PERI de la Plaça Sant Cugat (1992); PERI Sector Oriental Centre Históric. Porxos Fontseré, UA (1998); Estudi de Detall de la Residencia Lluis Companys (1991); Estudi de Detall de reordenació del volum relatiu al edifici del carrer Sant Pere més Baix núm. 7-9. Institut del Teatre (1990); Estudi de Detall del solar delimitat pels carrer Basea, Argenteria i Manresa (1989); Estudi de Detall del Sector Central del PERI del Sector Oriental. Avinguda Cambó (1994); Plà Especial d'ùsos de l'Estació de França (1995); PERI d'equipament docents al Passeig Pujades; Escola Superior de Comerç (1995); Modificació 
puntual PERI Sector Oriental en l'àmbit del Museo Picasso. Carrer Flasserders i l'Avinguda Cambó (1997); Modificació del PGM. Ordenació de terrenys, Estació de Rodalies, Passeig Circumvalació (1996); Modificació PERI Sector Oriental. Noves operacions d'habitatge protegit carrer Pou de la Figuera (1996); Estudi de Detall, en les tres illes del sector Portxos-carrer Rec (1997).

${ }^{13}$ U. Martínez Veiga (1999) Pobreza, segregación y exclusión social. La vivienda de los inmigrantes extranjeros en España, Barcelona, Institut Català de Antropologia-Icaria.

I4 De hecho, la gran mayoría de los antiguos residentes, según el responsable de una asociación de vecinos, han debido exiliarse hacia barrios periféricos, por no poder asumir el coste de los nuevos alquileres, aún cuando son modestos.

is Está ocupado por el CIDOB, organización no gubernamental especializada en el desarrollo y la cooperación. ${ }^{16}$ Cf. Escenas del Raval, op. cit.

17 A. Appadurai (1988): «Place and voice in anthropological theory», Cullural Anthropology, 3: 16-20.

is A notar que en la calle colindante se encuentra el Centre de Cultura Contemporánea de Barcelona (CCCB) y el Centre d'Estudis i Recursos Culturals (CERC), en edificios audazmente restaurados. Antes de las obras urbanísticas, esta parte constituía la antesala del Barrio Chino.

${ }^{19}$ Cf. D. Provansal (1992), Els Mercats de Barcelona, Ajuntament de Barcelona; también «Mercados, mercadi- llos, golosos y curiosos» (1999), Metrópolis, núm. 46, mayo-junio.

${ }^{20}$ El Mercat de Santa Catarina, el mercado cubierto de Barcelona más antiguo, era el lugar de predilección de los autóctonos. Desde que ha sido derribado y sustituido por un mercado provisional, cerca del Arc de Triomf, y por consiguiente situado bastante más lejos, los autóctonos consideran que el barrio, además de empeorar en muchos aspectos, ha perdido su identidad.

${ }_{21}$ El término designa la comunidad musulmana.

22 Se trata de la solidaridad basada en la «sangre».

23 I. Joseph (1997), «Le migrant comme tout venant», en M. Delgado (ed.), Ciutat i immigració, Centre de Cultura Contemporània de Barcelona, pp. 177-187.

${ }_{24}$ «Las ciencias sociales y las humanidades conciben las identidades como históricamente constituidas, imaginadas y reinventadas, en procesos constantes de hibridación y de transnacionalización, que disminuyen sus antiguos arraigos territoriales» (Consumidores y ciudadanos. Conflictos multiculturales de la globalización, Grijalbo, 1995, p. 92).

25 I. Joseph (1997), «Le migrant comme tout venant», en M. Delgado (ed.), Ciutat $i$ immigració, Centre de Cultura Contemporània de Barcelona, pp. 177-187.

26 «Las ciencias sociales y las humanidades conciben las identidades como históricamente constituidas, imaginadas y reinventadas, en procesos constantes de hibridación y de transnacionalización, que disminuyen sus antiguos arraigos territoriales" (Consumidores y ciudadanos. Conflictos multiculturales de la globalización, Grijalbo, 1995, p. 92).

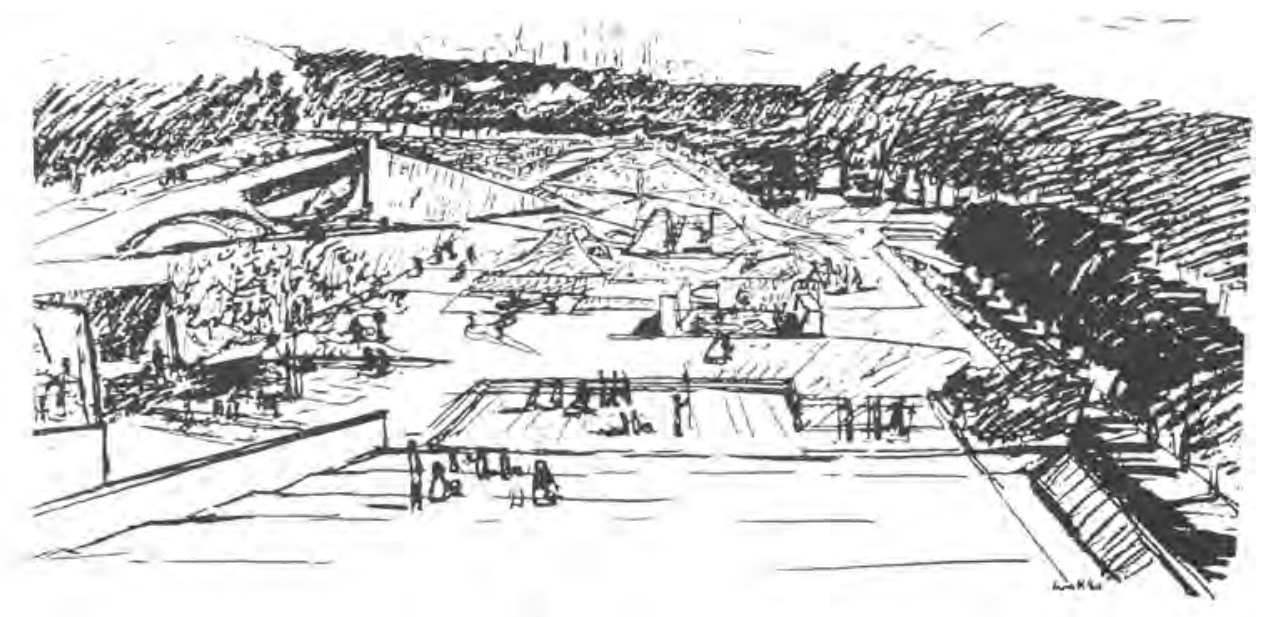

Louis I. Kahn, Isamo Noguchi - Área de juegos en el Levy Memorial New-York. 1961-66. 